\title{
0531. Cumulative effects of negative energy balance on myocardial deformity and diastolic function during the first week of ICU: a pilot study
}

\author{
A Gómez Blizniak*, DF Matallana Zapata, M Ruiz Bailén, A Morante, E Castillo-Lorente, MD Pola de Gallego, \\ F Ruiz Ferrón, J La Rosa, AM Castillo, L Rucabado Aguilar
}

From ESICM LIVES 2014

Barcelona, Spain. 27 September - 1 October 2014

\section{Objectives}

- To evaluate whether a greater negative energy balance (NEB) accumulated during the first week of ICU correlates with worsening in longitudinal Strain (LS) and diastolic function (DF).

- To evaluate whether improvement in the nutritional status (NS) correlates with improvement in LS and DF.

\section{Methods}

We made an observational, analytical, prospective, longitudinal pilot study.

\section{Dependents variables:}

$\boldsymbol{L S}$, echocardiographic parameter used to assess myocardial deformity (contraction). We considered as an improvement an increase $\geq 10 \%$.

E/é ratio, parameter used to assess $\mathrm{DF}$. A reduction of E/é ratio $\geq 10 \%$ was considered DF improvement.

\section{I. $V$,:}

NEB during the first week of admision.

Improvement in the NS: assessed by an increase in at least one level of prealbumin nutritional scale (PNS) after 10 days of receiving $100 \%$ of estimated energy (EE) requirements $(\mathrm{H}$. Benedict).

(PNS: Normal $>18 \mathrm{md} / \mathrm{dl}$, mild undernutrition: 17.9-15, moderate: $14.9-10$ severe $<10$ ).

Convenience nonprobability sample.

S. analysis: The results were expressed as means with their ST deviations, \%. Linear regression (LR) and Fisher test (FT) were used to analyze possible statistics associations, expressed with their $\mathrm{CI}$ and $\mathrm{p}$ values.

TTE were performed to patients admitted from July to October, 2013, in the first $24 \mathrm{~h}$ of admision, at 7th

Complejo Hospitalario de Jaén, Critical Care Unit, Jaén, Spain and 10th days of receiving enteral and/or parenteral nutrition with $100 \%$ of EE. Acoustic catches are done in HQ digital format, f.r.> $100 \mathrm{~Hz}$, for further analysis "of line" of LS. (Blind analysis).

Exclusion crit.: nephrotic syndrome, cirrhosis, chronic renal and HF.

PCR, MV (PEEP), PVC were recorded.

\section{Results}

10 patients, $60 \%$ male, mean age: 54 (27-75). $30 \%$ normal NS, $30 \%$ mild, $10 \%$ moderate and $30 \%$ severe undernutrition. $40 \%$ traumatic and $30 \%$ spontaneous $\mathrm{ICH}, 10 \%$ thoracic trauma , 10\% cardiac arrest and 10\% septic shock . $70 \%$ required $M V$, 20\% norepinephrine.

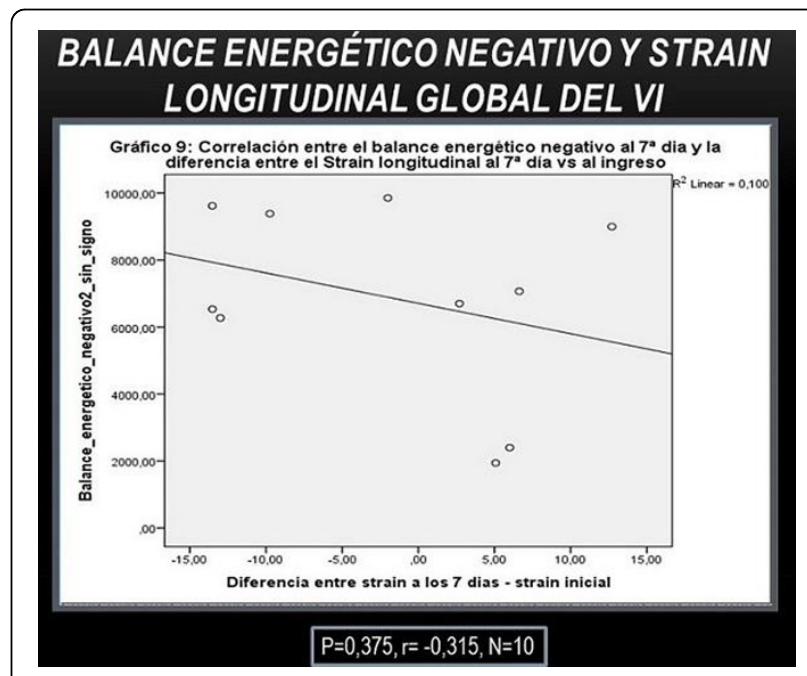

Figure 1 Longitudinal strain AND BEN 


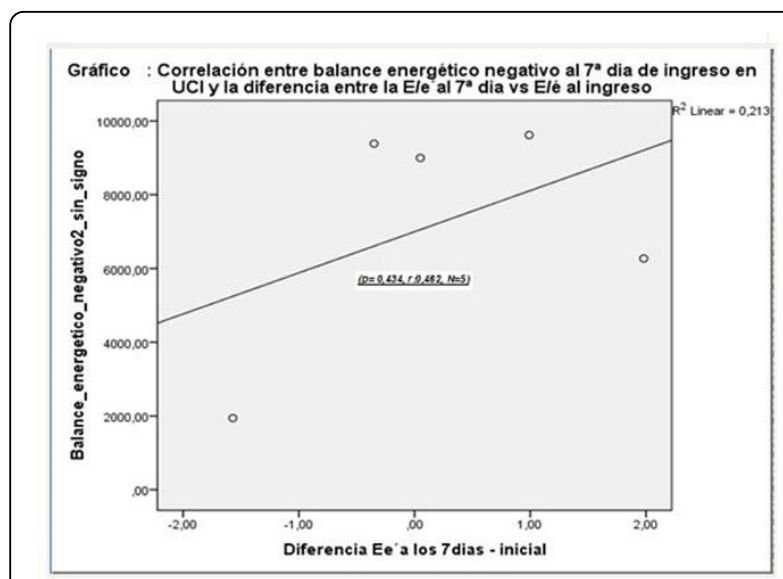

Figure 2 BEN AND DF

KS test: $\mathrm{p}=0.595$. We observe a tendency to an inverse relationship ( $\mathbf{p}=\mathbf{0 . 3 7 5}, \mathrm{r}=-0.315, \mathrm{~N}=10$ ) between NEB and LS but not s. significant. $40 \%$ of those who had improvement in at least 1 level of the PNS showed a 10\% increase in LV LS at 10 days receiving 100\% EE (FT: $\mathbf{p}=$ 0.714, OR: $0.667,95 \% \mathrm{CI}: 0.025$ to 18.059 ).

As in the Hammer et al study [1], in which acute progressive caloric restriction in young healthy men correlated with impaired DF, we observed a direct relationship $(\mathrm{r}=0.462, \mathrm{p}=0.434, \mathrm{~N}=5)$ between NEB and E/é, but not s. significant. The $50 \%$ who had an improvement in NS showed a $10 \%$ reduction in E /é (FT: $\mathbf{p}=\mathbf{1 . 0 0}$, OR $1.00,95 \%$ CI : 0.03 to 29 ).

\section{Conclusions}

Patients with higher cumulative NEB during the first week of ICU had a decrease in LS and an increase in E/é but not s. significant. Given the limitations of this research (being a pilot study of a topic not addressed in ICU with few patients) should be carried further study with sufficient power to test this hypothesis.

Published: 26 September 2014

\section{Reference}

1. Hammer et al: Progressive caloric restriction induces dose-dependent changes in myocardial triglyceride content and diastolic function in healthy men J Clin Endocrinol Metab 2008, 93(2):497-503.

doi:10.1186/2197-425X-2-S1-P31

Cite this article as: Blizniak et al.: 0531. Cumulative effects of negative energy balance on myocardial deformity and diastolic function during the first week of ICU: a pilot study. Intensive Care Medicine Experimental 20142 (Suppl 1):P31.

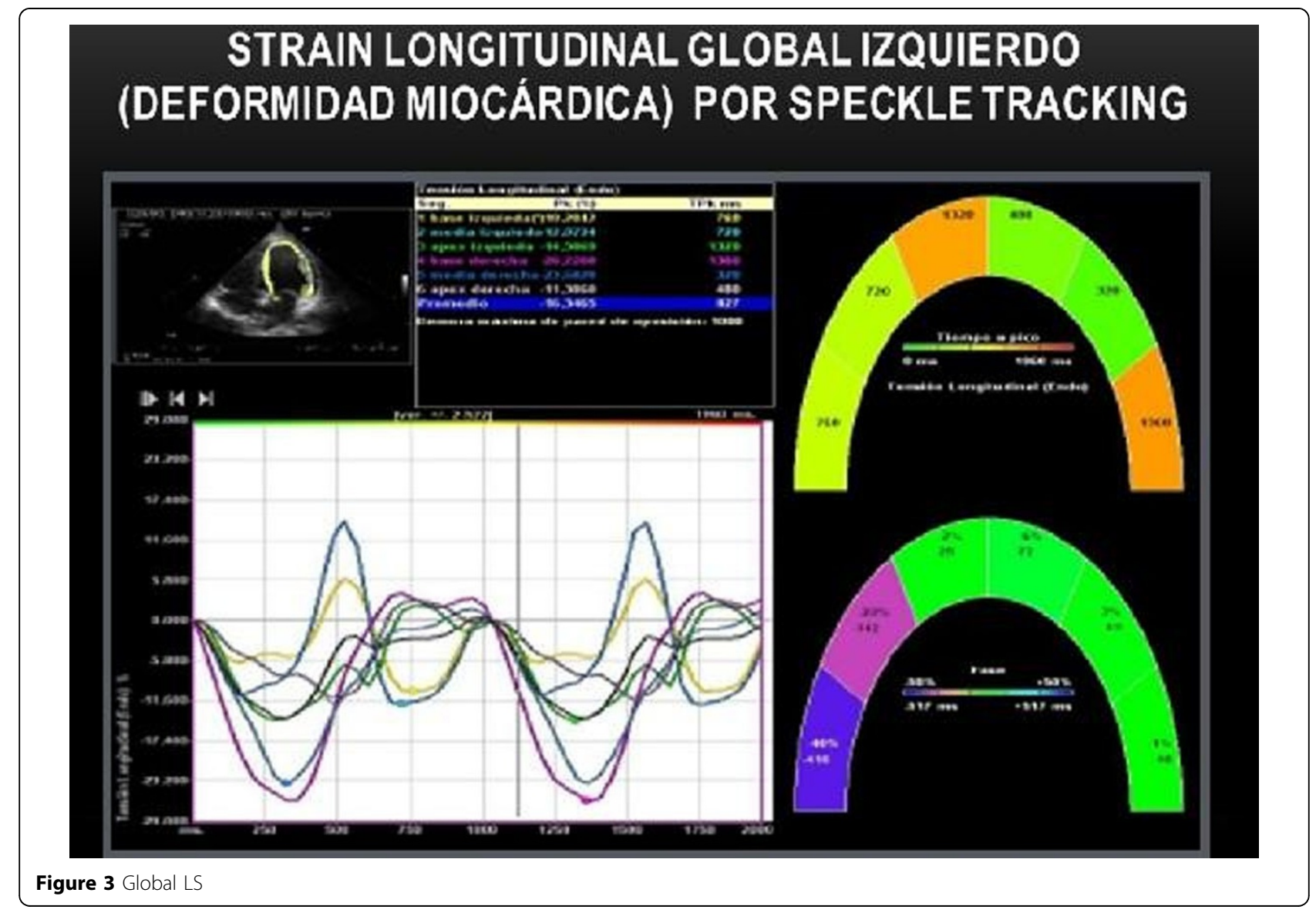

